\title{
Social capital and factors associated with the caries experience in adults - a population-based study in Brazil
}

\author{
Jamille Silva NOGUEIRA ${ }^{(a)}$ (ii) \\ Antonio Carlos PEREIRA(a) (it) \\ Antonio Carlos FRIAS(b) (ID) \\ Gláucia Maria Bovi AMBROSANO(a) \\ Karine Laura CORTELLAZZI(a) (D) \\ Luciane Miranda GUERRA(a) (iD) \\ Denise de Fátima Barros \\ CAVALCANTE(a) \\ Jaqueline Vilela BULGARELI(c) \\ (a) Universidade Estadual de Campinas - \\ Unicamp, School of Dentistry of Piracicaba, \\ Department of Social Dentistry, Piracicaba, \\ SP, Brazil. \\ (b) Universidade de São Paulo - USP, Faculty \\ of Dentistry, Department of Social Dentistry, \\ São Paulo, SP, Brazil. \\ (c) Universidade Federal de Uberlândia - \\ UFU, Department of Preventive and Social \\ Dentistry, Uberlândia, MG, Brazil.
}

Declaration of Interests: The authors certify that they have no commercial or associative interest that represents a conflict of interest in connection with the manuscript.

\section{Corresponding Author:}

Jamille Silva Nogueira

E-mail: jamille_snogueira@hotmail.com

https://doi.org/10.1590/1807-3107bor-2019.vol33.0118

Submitted: May 7, 2019

Accepted for publication: October 9, 2019

Last revision: October 30, 2019

\begin{abstract}
The objective of this study was to investigate the experience of caries related to social capital and associated factors in adults in large-scale population-based study. A Cross-sectional study was performed in 163 municipalities in the State of São Paulo, Brazil (SBSP-2015). 17,560 people were evaluated, of which 6051 were adults aged 35-44 years. Hierarchical logistic regression analysis was proposed. Outcome variables (decayed teeth, missing teeth and DMFT) and independent variables were included in the model, considering the distal (income and schooling); intermediate (social capital) and proximal levels (sex and ethnicity). Results showed that income up to 1,500 reais - US\$ 367.6 in 11/11/2019 - (OR = 1.91;1.75-2.08), schooling up to 8 years $(\mathrm{OR}=1.32 ; 1.12-1.56)$ and non-white ethnicity $(\mathrm{OR}=1.54 ; 1.35-1.76)$ were more likely to have decayed teeth. Income up to 1500 reais $(\mathrm{OR}=1.29 ; 1.15-1.44)$, schooling up to 8 years $(\mathrm{OR}=2.13 ; 1.90-2.38)$, low social capital $(\mathrm{OR}=1.84 ; 1.65-2.04)$, medium social capital $(\mathrm{OR}=1.15 ; 1.01-1.30)$ and females were more likely to have lost teeth $(\mathrm{OR}=1.13 ; 1.03-1.23)$. Schooling up to 8 years $(\mathrm{OR}=1.51 ; 1.35-1.69)$, low social capital $(\mathrm{OR}=1.25 ; 1.14-1.37)$ and female $(\mathrm{OR}=1.40,1.19-1.53)$ were associated with DMFT. It was concluded that sociodemographic factors and low social capital were associated with the experience of caries, which should be taken into account in the formulation of public policies.
\end{abstract}

Keywords: Oral Health; Adult; Epidemiology; Dental Caries.

\section{Introduction}

Historically, oral health in Brazil has prioritized the care to schoolage children. ${ }^{1,2}$ Thus, the offer of services for the adult population was limited to curative and mutilating actions, ${ }^{3}$ focusing on dental extractions. ${ }^{4}$ Recent epidemiological surveys in oral health conducted in Brazil (2010) and in the state of São Paulo (2015) indicated high percentages of adults in need for oral health treatment, with 83\% (Brazil) and 74\% (São Paulo) requiring periodontal treatment and 69 and 52\% (respectively) in need of prosthesis. In addition, a high rate of caries was found - average DMFT decayed component of 1.9 and 1.53 , missing teeth of 7.3 and 6.3 , and total DMFT of 16.7 and 15, respectively. ${ }^{5,6}$

Another important point in studies on risk factors for dental caries is the population self-perception on dental health. Self-perception is 
related to different biological factors, and individual and contextual social determinants. Thus, poor oral hygiene is associated to fewer years of education, lower per capita income, higher income inequality, and worse human development. ${ }^{7}$

In addition, there is a strong relationship between income inequality and oral health problems. ${ }^{8}$ Studies reveal that worse social position and weaker social bonds, such as social capital, are important indicators for the loss of teeth. ${ }^{9}$ Severe dental loss and lack of a functional dentition are results of income inequality among Brazilian adults. ${ }^{10}$ In several countries, socioeconomic level had a significant influence on oral health among adults. $8,11,12,13$

Therefore, "social capital" is part of the social features of the individual, and includes social networking resources, such as interpersonal trust, reciprocity norms, ${ }^{14,15}$ and normative foundations able to produce social integration. ${ }^{16}$ Social capital can accentuate or mitigate the negative effect of socioeconomic factors on the health of the population. ${ }^{17}$

There are few epidemiological studies that explore the various factors involved in the individual's social context, especially social capital, using conceptual models to determine the caries experience of a population..$^{18}$ Although some studies with probabilistic samples developed in Brazil have brought important contributions about theoretical frameworks and prevalence of caries in adults, certainly none of them had a large enough sample to allow generalization of the data for such a populous region as the state of São Paulo in Brazil - over 40 million people. Therefore, the representativeness and generalization capacity of the results are a differential of this study.

Furthermore, the planning of actions, strategies, programs, and policies on oral health aimed at preventing oral diseases in the adult population must be encouraged. The knowledge of caries experience, oral health self-perception as well as the influence and impact of social factors, especially social capital is of paramount importance. This is contained in social factors or determinants and is little emphasized in studies.

Thus, the goal of this study was to investigate the caries experience and its association to social capital and other factors in adults in the state of São Paulo.

\section{Methodology}

The was a cross-sectional study with secondary data from the State Research on Oral Health, funded by the government of São Paulo and conducted from January to September $2015^{5}$ in adolescents, adults, and older adults. Data from the main study are available on the website of the School of Dentistry of PiracicabaFOP/Unicamp, at: http://w2.fop.unicamp.br/sbsp2015/ or Figshare public data repository-License CC BY 4.0 with DOI:10.6084/m9.figshare.5286025.v1.

The sample size was calculated based on the average (18.32) and standard deviation (14.61) of the DMFT index, with an acceptable margin of error $(\varepsilon)$ of 0.10 , design effect (deff) $=2$, and non-response rate (NRR) of $30 \%$.

This study was representative of 6 macro-regions of São Paulo, called domains, and 33 municipalities were selected from each domain, called primary sampling units (UPAs). The exception was the metropolitan region of the capital, where 12 municipalities, in addition to the capital, were selected. Three hundred and ninety census tracts (two sectors for 177 cities and 36 sectors for the city of São Paulo) were selected. All households of the selected sectors were visited to find eligible people, using the technique of exhaustion with a minimum sample size for each primary sampling unit.

The sampling fractions were corrected according to the NNR for each step of the draft. Individuals who refused to participated and those absent at the moment of visit were excluded, totaling 17,560 people examined in 163 municipalities, being 6,051 in the age group of 35-44 years (as recommended by $\mathrm{WHO})^{5}$

A total of 253 oral health teams (each composed of a dentist and a dental assistant) participated in the study. The teams were trained in a workshop with duration of 16 hours aimed to discuss the implementation of the work steps, the assignments of each participant, and to ensure an acceptable standardization of procedures. The calibration process lasted 24 hours and was conducted by a experienced examiner to ensure standardization and agreement among teams. ${ }^{5}$ The consensus technique was used by calculating the Kappa 
coefficient weighted for each examiner, age group, and condition studied, taking the value of 0.65 as the minimum acceptable threshold. ${ }^{6}$

In the survey, caries experience was evaluated by the DMFT index, number of carious teeth, and number of missing teeth, according to the codes and criteria recommended by the World Health Organization..$^{19}$ Data related to sociodemographic conditions (household income, education level, sex and ethnicity, and social capital were also collected. Previously trained and calibrated dentists performed the oral examination and the application of questionnaires in the participant's home. ${ }^{5}$

For the social capital variable, questions from the SB SP 2015 forms were applied, which were extracted from the Integrated Questionnaire for the Measurement of Social Capital (SC-IQ). As the questionnaire does not have a final score, the researchers decide on how to use it. ${ }^{20}$ Questions assess the levels of cooperation, safety, and happiness. The safety level was given through the following item: "Overall, how do you fell about crime and violence when you're home alone?" (Grouped into: 1-very and moderately safe, 2-very and moderately unsafe, 3-nither safe nor unsafe). The item regarding cooperation was: "If there was a problem of water supply in this community, what are the odds that people will cooperate to try and solve the problem?" (Grouped into: 1-very and relatively likely, 2-very and relatively unlikely, 3-nither likely nor unlikely). The level of happiness were grouped into: a) very and moderately happy, b) very and moderately unhappy, 3-nither happy nor unhappy. The answers were grouped according to the sum of the codes in the answers of levels 1, 2, and 3 to obtain the reference of high, medium, and low social capital (high: 3-4; medium: 5-6; and low: 7-9).

The dependent variables were the DMFT index (dichotomized by the median into $<16$ and $>16$ ), number of decayed teeth (dichotomized by the median into 0 and $>0$ ), and number of missing teeth (dichotomized by the median into $<4$ and $>4$ ).

The hypotheses of this study (H1) were as follows: a) there is an association between social capital and caries experience and $b$ ) there is an association between socioeconomic variables and caries experience, both hypotheses for the adult population.

Independent variables were collected into 3 levels. The distal level (social structure) included income (dichotomized into up to $\mathrm{R} \$ 1,500$ and > $\mathrm{R} \$ 1,500)$ and education level (dichotomized into up to 8 years of study and $>8$ years of study). At the intermediate level (social context) was the social capital (categorized into high, medium, and low). In addition, at the proximal level (individual level) were included sex (male, female) and ethnicity (white and non-white).

Variables were organized based on a conceptual model with hierarchical modeling for the multiple analysis of tooth decay predictors. ${ }^{18}$ Independent variables were included in levels, starting by the social structure (distal) up to the individual (proximal) ones, taking the outcome as reference (Figure).

The weights calculated from the sampling plan were used to adjust the estimates according to the distribution within the regions, in order to correct any sample discrepancy due to selection. Hierarchical logistic regression analysis was used to analyze

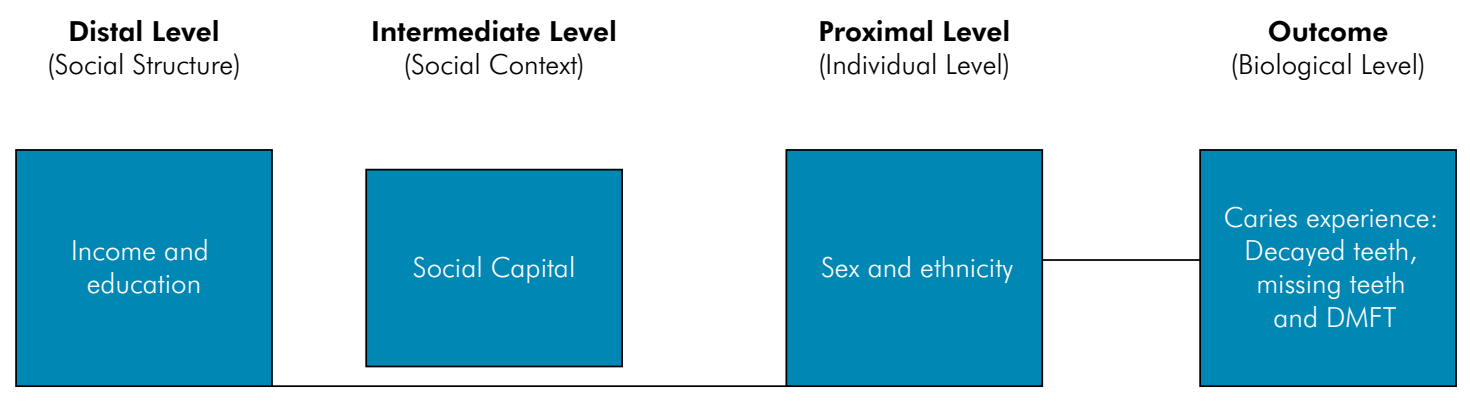

Figure. Conceptual model adapted from Holst et al. ${ }^{18}$ 
the association between the presence of caries, missing teeth, and DMFT (outcome variables), and the independent variables. Income and education were considered in the distal block for the entry of the variables in the model; social capital was in the mesial block, and sex and ethnicity in the proximal block. ${ }^{18}$ The variables were entered in the model sequentially (hierarchically), with the statistical significance of $a=0.05$ and the quality of fit assessed by the Akaike information criterion (AIC) and $-2 \log \mathrm{L}$, as described in Table 1. All analyzes were performed using the SAS program. ${ }^{21}$

The Research Ethics Committee of Piracicaba Dental School at University of Campinas, Brazil (CEP/FOP No.041/2018), exempted the study from ethical approval because it included secondary, public, and unrestricted access data from the state epidemiological survey on oral health. All participants examined in the study signed the informed consent form. ${ }^{5}$

\section{Results}

Of the total sample, $67.9 \%$ was female, $62.0 \%$ white, 58.1\% had and income over $\mathrm{R} \$ 1,500,56.3 \%$ had an education level above 8 years of study, $66 \%$ was classified as having high social capital (Table 2).

Table 3 shows the results of crude and adjusted analyses for the number of decayed teeth, missing teeth, and DMFT. Results showed that income up to $\mathrm{R} \$ 1,500(\mathrm{OR}=1.91 ; 1.75-2.08)$, education level up to 8 years $(\mathrm{OR}=1.32 ; 1.12-1.56)$, and non-white ethnicity $(\mathrm{OR}=1.54 ; 1.35-1.76)$ were related to more chances of having carious teeth. Income up to $\mathrm{R} \$ 1,500(\mathrm{OR}=1.29$; 1.15-1.44), education level up to 8 years $(\mathrm{OR}=2.13$;
1.90-2.38), low social capital (OR $=1.84 ; 1.65-2.04)$, medium social capital (OR $=1.15 ; 1.01-1.30)$, and female sex led to higher chances of missing teeth $(\mathrm{OR}=1.13$; 1.03-1.23). Education level up to 8 years $(\mathrm{OR}=1.51 ; 1.35-1.69)$, low social capital $(\mathrm{OR}=1.25$; 1.14-1.37), and female sex (OR $=1.40 ; 1.19-1.53)$ were associated with the DMFT. Non-white ethnicity was a protection variable $(\mathrm{OR}=0.80 ; 0.72-0.90)$ for caries experience (DMFT).

\section{Discussion}

This study has shown that people with lower income had a worse caries experience regarding decayed and missing teeth. The access to oral health services, currently still limited for the lowerincome population, may justify the results found. Furthermore, the lower-income population also consume more sugar-containing foods of low nutritional value, which partially explains the higher prevalence of caries in this population. ${ }^{22}$ Given the high prevalence of caries and the limitation of treatment resources, the greater tooth loss found in this study was expected, which also confirms the results of another study. ${ }^{23}$ To this end, public policies aimed at improving the oral health of the population work best when supported by policies to promote less income inequality. ${ }^{8}$

The relationship between missing teeth and education level is inversely proportional. The fact that individuals with less schooling are more predisposed to tooth loss can be explained by them seeking treatment less often, ${ }^{24}$ whether due to difficult access to services at different levels of treatment complexity, transportation, or distance from the healthcare center.

Table 1. Goodness of fit (Akaike information criterion - AICC; -2 Log L).

\begin{tabular}{lcccccc}
\hline \multirow{2}{*}{ Model } & \multicolumn{3}{c}{ AICC } & & & \multicolumn{2}{c}{-2 Log L } \\
\cline { 2 - 6 } & Decayed & Missing & DMFT & Decayed & Missing & DMFT \\
\hline Empty & 33122654 & 33124097 & 38442304 & 33122652 & 33124095 & 38442302 \\
Distal level & 32165851 & 32101157 & 38192529 & 32165825 & 32101151 & 38192525 \\
Distal+lntermediate level & - & 31971077 & 38086825 & - & 31971067 & 38086817 \\
Final Model & 31913993 & 31954014 & 37822022 & 31913985 & 31954002 & 37822010 \\
\hline
\end{tabular}


Table 2. Frequency distribution and weighted prevalence for the number of decayed and missing teeth, and DMFT regarding the variables analyzed.

\begin{tabular}{|c|c|c|c|c|}
\hline \multirow[t]{2}{*}{ Variable } & Total & $\begin{array}{l}\text { Weighted prevalence } \\
\text { for decayed teeth }\end{array}$ & $\begin{array}{l}\text { Weighted prevalence } \\
\text { for missing teeth }\end{array}$ & $\begin{array}{l}\text { Weighted prevalence } \\
\text { for DMFT }\end{array}$ \\
\hline & $\mathrm{n}(\%)^{\mathrm{a}}$ & $\%$ Decayed $>0^{b}$ & $\%$ Missing $>4^{\#}$ & $\% \mathrm{DMFT}>16^{\#}$ \\
\hline \multicolumn{5}{|l|}{ Distal level } \\
\hline \multicolumn{5}{|l|}{ Income } \\
\hline$<\mathrm{R} \$ 1,500$ & 2224 (41.9) & 55.7 & 60.3 & 50.4 \\
\hline$>\mathrm{R} \$ 1,500$ & $3085(58.1)$ & 37.7 & 50.0 & 50.0 \\
\hline \multicolumn{5}{|c|}{ Education level (years of study) } \\
\hline Up to 8 & $2470(43.7)$ & 52.9 & 66.6 & 56.5 \\
\hline$>8$ years & $3183(56.3)$ & 40.6 & 45.4 & 47.0 \\
\hline \multicolumn{5}{|l|}{ Intermediate level } \\
\hline \multicolumn{5}{|l|}{ Social capital } \\
\hline Low & $313(5.3)$ & 53.2 & 68.7 & 56.6 \\
\hline Medium & $1680(28.6)$ & 48.2 & 57.2 & 50.3 \\
\hline High & $3872(66.0)$ & 44.8 & 52.6 & 50.5 \\
\hline \multicolumn{5}{|l|}{ Proximal Level } \\
\hline \multicolumn{5}{|l|}{ Sex } \\
\hline Male & $1943(32.1)$ & 47.7 & 52.0 & 45.2 \\
\hline Female & 4108 (67.9) & 45.3 & 57.2 & 54.4 \\
\hline \multicolumn{5}{|l|}{ Ethnicity } \\
\hline White & $3763(62.2)$ & 41.0 & 55.0 & 52.9 \\
\hline Non-white & $2288(37.8)$ & 53.7 & 56.5 & 49.6 \\
\hline
\end{tabular}

apercentage are shown in columns; ${ }^{b}$ Decayed $>0$. Missing $>4 \#$. DMFT > 16\#; cPrevalence are shown lines. DMFT: index of permanent teeth that are decayed, missing and filled. ${ }^{\#}$ Median.

Individuals with greater number of decayed teeth and less than 8 years of education certainly had less access to educational programs for the prevention of caries than those with more years in school, where children and adolescents of our study were exposed to educational actions in health. ${ }^{25}$ Thus, children who remained in school probably have higher income, greater social support, and increased access to healthy food.

The greater number of missing teeth and higher DMFT observed in women in this study may be explained by the greater frequency of women in oral health services than adult men. ${ }^{26} \mathrm{~A}$ prior study ${ }^{4}$ had already identified such relationship between missing teeth and female sex. The main motivations for the greater frequency of women in dental consultations are pregnancy and greater adherence to prevention programs. ${ }^{27}$
The relationship between social capital and caries experience (DMFT and missing teeth) was clear in this study and highlights the importance solidarity and support, which may positively impact various aspects of a society, especially the health of individuals. In this case, people with lower social capital had a greater number of missing teeth, as well as a higher DMFT. Probably the historical heritage of a mutilating dental practice that affected these individuals' dentition, combined with the difficulty of access to dental treatment in younger ager resulted in several damages and accumulated needs. Individuals within groups with high social capital have better conditions of getting dental treatment, whether by non-governmental and solidarity entities, social organizations, help of friends etc., than those who cannot count on such help. The already accumulated needs of the latter raises the number of missing 
Table 3. Crude and adjusted analyses for the number of decayed and missing teeth, and DMFT regarding the variables analyzed.

\begin{tabular}{|c|c|c|c|c|c|c|}
\hline \multirow[b]{2}{*}{ Variable } & \multicolumn{2}{|c|}{ Decayed $>0 *$} & \multicolumn{2}{|c|}{ Missing $>4^{* *}$} & \multicolumn{2}{|c|}{ DMFT $>16^{* *}$} \\
\hline & $\begin{array}{l}\text { Crude weighted } \\
\text { OR (IC95\%) }\end{array}$ & $\begin{array}{l}\text { Adjusted weighted } \\
\text { OR (IC95\%) }\end{array}$ & $\begin{array}{l}\text { Crude weighted } \\
\text { OR (IC95\%) }\end{array}$ & $\begin{array}{c}\text { Adjusted weighted } \\
\text { OR (IC95\%) }\end{array}$ & $\begin{array}{l}\text { Crude weighted } \\
\text { OR (IC95\%) }\end{array}$ & $\begin{array}{c}\text { Adjusted weighted } \\
\text { OR (IC95\%) }\end{array}$ \\
\hline \multicolumn{7}{|l|}{ Distal level } \\
\hline \multicolumn{7}{|l|}{ Income } \\
\hline$<\mathrm{R} \$ 1,500$ & $\begin{array}{c}* 2.11 \\
(1.95-2.28)\end{array}$ & $\begin{array}{c}{ }^{*} 1.91 \\
(175-2.08)\end{array}$ & $\begin{array}{c}{ }^{*} 1.51 \\
(1.34-1.71)\end{array}$ & $\begin{array}{c}* 1.29 \\
(1,15-1.44)\end{array}$ & $\begin{array}{c}1.02 \\
(0.88-1.17)\end{array}$ & \\
\hline$>\mathrm{R} \$ 1,500$ & Ref & Ref & Ref & Ref & Ref & \\
\hline \multicolumn{7}{|c|}{ Education level (years of study) } \\
\hline Up to 8 & $\begin{array}{c}{ }^{*} 1.64 \\
(1.42-1.90)\end{array}$ & $\begin{array}{c}{ }^{*} 1.32 \\
(1.12-1.56)\end{array}$ & $\begin{array}{c}* 2.40 \\
(2.16-2.68)\end{array}$ & $\begin{array}{c}{ }^{*} 2.13 \\
(1.90-2.38)\end{array}$ & $\begin{array}{c}{ }^{*} 1.47 \\
(1.30-1.65)\end{array}$ & $\begin{array}{c}{ }^{*} 1.51 \\
(1.35-1.69\end{array}$ \\
\hline$>8$ years & Ref & Ref & Ref & Ref & Ref & Ref \\
\hline \multicolumn{7}{|l|}{ Intermediate level } \\
\hline \multicolumn{7}{|l|}{ Social capital } \\
\hline Low & $\begin{array}{c}{ }^{*} 1.40 \\
(1.29-1.52)\end{array}$ & & $\begin{array}{c}{ }^{*} 1.97 \\
(1.80-2.16)\end{array}$ & $\begin{array}{c}{ }^{*} 1.84 \\
(1.65-2.04)\end{array}$ & $\begin{array}{c}{ }^{*} 1.28 \\
(1.16-1.41)\end{array}$ & $\begin{array}{c}{ }^{*} 1.25 \\
(1.14-1.37)\end{array}$ \\
\hline Medium & $\begin{array}{c}{ }^{*} 1.14 \\
(1.03-1.27)\end{array}$ & & $\begin{array}{c}{ }^{*} 1.20 \\
(1.06-1.37)\end{array}$ & $\begin{array}{c}{ }^{*} 1.15 \\
(1.01-1.30)\end{array}$ & $\begin{array}{c}0.99 \\
(0.86-1.14)\end{array}$ & $\begin{array}{c}1.00 \\
(0.86-1.15)\end{array}$ \\
\hline High & Ref & & Ref & Ref & Ref & Ref \\
\hline \multicolumn{7}{|l|}{ Proximal level } \\
\hline \multicolumn{7}{|l|}{ Sex } \\
\hline Male & Ref & & Ref & Ref & Ref & Ref \\
\hline Female & $\begin{array}{c}0.91 \\
(0.81-1.01)\end{array}$ & & $\begin{array}{c}{ }^{*} 1.23 \\
(1.12-1.35)\end{array}$ & $\begin{array}{c}{ }^{*} 1.13 \\
(1.03-1.23)\end{array}$ & $\begin{array}{c}* 1.44 \\
(1.31-1.58)\end{array}$ & $\begin{array}{c}* 1.40 \\
(1.19-1.53)\end{array}$ \\
\hline \multicolumn{7}{|l|}{ Ethnicity } \\
\hline White & Ref & Ref & Ref & & Ref & Ref \\
\hline Non-white & $\begin{array}{c}{ }^{*} 1.67 \\
(1.51-1.86)\end{array}$ & $\begin{array}{c}{ }^{*} 1.54 \\
(1.35-1.76)\end{array}$ & $\begin{array}{c}1.06 \\
(0.98-1.16)\end{array}$ & & $\begin{array}{c}* 0.87 \\
(0.78-0.98)\end{array}$ & $\begin{array}{c}* 0.80 \\
(0.72-0.90)\end{array}$ \\
\hline
\end{tabular}

${ }^{*} \mathrm{p} \leq$ 0.05. "Median. DMFT: index of permanent teeth that are decayed, missing and filled.

teeth in this group and, consequently, the DMFT. ${ }^{28}$ Therefore, even individuals with lower income and education level, and less opportunities may have had a high social capital, such as social benefits, support from neighbors, friends and relatives, and group participation.

Another study has associated tooth loss with low social capital, older adults, and low education level. However, age was the decisive factor for tooth loss, regardless of education or income per capita in the group with high social capital. Hence, tooth loss was explained by social capital, age, and income. ${ }^{17}$ Social capital can be a mechanism through which income inequalities negatively affect health factors. Countries with weak social cohesion caused by income iniquities invest less in human capital and social support networks, which are fundamental for the promotion and protection of individual and collective health. ${ }^{29}$ This study shows that social capital significantly impacts the prevalence of caries. Although social capital was assessed at the time of the oral exam, the health-disease process of caries was developed over the life of the individual. In this sense, social capital should be interpreted with caution. When determining the effect of social capital on caries experience, this study makes use of the assumption that the social capital measured at the time of examinations was the same throughout the individual's life, thus contributing to the healthdisease process of caries. From the point of view of 
health managers, the relationship between social capital and the health-disease process is relevant for the implementation of policies that impact directly the social support networks, reduce inequities, and focus in the human capital.

The adult age group still suffers with a health system that, in the past, emphasized the oral health of children. These adults, in turn, opt for dental extractions due to the cost of endodontic treatment. Overall, the option for tooth extraction instead of restorative treatment is a result of the high waiting time to access secondary care, elevated caries progression and lack of access to a more complex restorative treatment, need for a greater number of dental visits for solving the problem (which implies greater transportation cost and loss of working hours), among other issues. ${ }^{30}$

Although non-white individuals had a significantly greater index of decayed and missing teeth than white participants, the opposite occurred for DMFT, which was reduced in non-whites. This can be explained by the fact that non-white individuals and those less socioeconomically favored are among those that most benefit from the Programa Brasil Sorridente (Smily Brazil Program). The guiding paradigm of this policy is the promotion of health and prevention. On the other hand, individuals more socially advantaged usually are more able to get dental treatment, usually private, which generally follows a paradigm that is more restorative than health promoter compared to the aforementioned National Health Policy. ${ }^{31}$ This obviously increases the restored component of DMFT in white people.

A limitation of this study was the difficulty in determining causal relationships and affirming whether the associations occur prior or after the obtained results, as this is a cross-sectional study. However, as we obtained results from a probabilistic sample by population conglomerates of the state of
São Paulo, these data are reliable and become relevant to other states, regions, or countries with similar characteristics. ${ }^{32}$ Therefore, public administrators can use these results and associations to guide actions aiming at improving the current framework of caries experience, investing in measures such as increasing health promotion, prevention, and care, extending social support networks and human capital, as well as reducing iniquities.

Our results are comparable to prior epidemiological surveys conducted in the Brazilian adult population, as caries experience framework did not change, and the factors related to inequality in oral health, such as income, education level, ethnicity, sex, access to services, and social capital, are still the same. Nonetheless, these reflections must be fully exploited in our country, with the expansion of studies related to social capital, and the action on other factors related to the health-disease process should be emphasized. Although the provision of dental services has grown over the years, it is still insufficient to meet the oral health needs of the adult population. Thus, policies about health aspects should offer promotion, prevention, and rehabilitation, as well as improve income and education and focus on the social context.

\section{Conclusion}

Sociodemographic factors were associated with caries experience; women and people with low social capital were associated with higher DMFT (total caries experience) and missing teeth (partial), which should be taken into account in the formulation of public policies.

The authors thank "Espaço da Escrita-Pró-Reitoria de Pesquisa-UNICAMP"-for the language services provided and all of 650 professionals of public health services involved in this study.

\section{References}

1. Narvai PC FP. Saúde bucal no Brasil: muito além do céu da boca. Rio Janeiro Ed Fiocruz. 2008. https://doi.org/10.7476/9788575413630.

2. Nickel DA, Lima FG, Silva BB. [Dental care models in Brazil]. Cad Saude Publica. 2008 Feb;24(2):241-6. Portuguese. https://doi.org/10.1590/S0102-311X2008000200002 
3. Groisman S, Moraes NM. A evolução da atenção à saúde no Brasil: o contexto da saúde bucal. Brasília, DF: Cad da ABOPREV II; 2005.

4. Barbato PR, Muller Nagano HC, Zanchet FN, Boing AF, Peres MA. [Tooth loss and associated socioeconomic, demographic, and dental-care factors in Brazilian adults: an analysis of the Brazilian Oral Health Survey]. Cad Saude Publica. 2007 Aug;23(8):1803-14. Portuguese. https://doi.org/10.1590/S0102-311X2007000800007

5. Pereira AC, Vieira V, Frias AC. SB São Paulo: pesquisa estadual de saúde bucal 2015: relatório final. Águas de São Pedro: Livronovo, 2016.

6. Ministério da Saúde (BR). Secretaria de Vigilância em Saúde. Secretaria de Atenção à Saúde. Resultados principais. SB Brasil 2010. Pesquisa Nacional de Saúde Bucal. Brasília, DF: Ministério da Saúde; 2012.

7. Silva JV, Oliveira AG. Individual and contextual factors associated to the self-perception of oral health in Brazilian adults. Rev Saude Publica. 2018 Apr;52:29. https://doi.org/10.11606/S1518-8787.2018052000361

8. Moeller J, Quiñonez C. The association between income inequality and oral health in Canada: a cross-sectional study. Int J Health Serv. 2016 Oct;46(4):790-809. https://doi.org/10.1177/0020731416635078

9. Vettore MV, Faerstein E, Baker SR. Social position, social ties and adult's oral health: 13 year cohort study. J Dent. 2016 Jan;44:50-6. https://doi.org/10.1016/i.jdent.2015.12.004

10. Goulart MA, Vettore MV. Is the relative increase in income inequality related to tooth loss in middle-aged adults? J Public Health Dent. 2016;76(1):65-75. https://doi.org/10.1111/iphd.12113

11. Arrica M, Carta G, Cocco F, Cagetti MG, Campus G, lerardo G, et al. Does a social/behavioural gradient in dental health exist among adults? A cross-sectional study. J Int Med Res. 2017 Apr;45(2):451-61. https://doi.org/10.1177/0300060516675682

12. Hakeberg M, Wide Boman U. Self-reported oral and general health in relation to socioeconomic position. BMC Public Health. BMC Public Health. 2017;18(1):63. https://doi.org/10.1186/s12889-017-4609-9.

13. Rozier RG, White BA, Slade GD. Trends in Oral Diseases in the U.S. Population. J Dent Educ. 2017 Aug;81(8 8s):eS97-109. https://doi.org/10.21815/JDE.017.016 PMID:28765461

14. Kawachi I, Kennedy BP, Lochner K, Prothrow-Stith D. Social capital, income inequality, and mortality. Am J Public Health. 1997 Sep;87(9):1491-8. https://doi.org/10.2105/AJPH.87.9.1491

15. Putnam RD. Making democracy work: civil traditions in modern Italy. City: Princeton University Press; 1993. 275 pp.

16. Coleman JS. Social capital in the creation of human captial. Am J Sociol. 1988;94:S95-120. https://doi.org/10.1086/228943

17. Borges CM, Campos AC, Vargas AM, Ferreira EF. [Adult tooth loss profile in accordance with social capital and demographic and socioeconomic characteristics]. Cien Saude Colet. 2014 Jun;19(6):1849-58. Portuguese. https://doi.org/10.1590/1413-81232014196.02332013

18. Holst D, Schuller AA, Aleksejuniené J, Eriksen HM. Caries in populations: a theoretical, causal approach. 2001 June;109(3):143-8. https://doi.org/10.1034/j.1600-0722.2001.00022.x

19. World Health Organization. Oral health surveys: basic methods. 5th ed. Geneva: World Health Organization; 2013.

20. Grootaert C, Narayan D, Jones VN, Woolcock M. Measurement of social capital: na integrated questinnaire. Washington, DC: The World Bank; 2004. (World Bank working paper, Vol. 18).

21. SAS Institute Inc. SAS/STAT Guide for personal computers: version 9.4. Cary: SAS Institute Inc; 2001.

22. Bernabé E, Vehkalahti MM, Sheiham A, Aromaa A, Suominen AL. Sugar-sweetened beverages and dental caries in adults: a 4-year prospective study. J Dent. 2014 Aug;42(8):952-8. https://doi.org/10.1016/i.jdent.2014.04.011

23. Batista MJ, Lawrence HP, Sousa ML. [Tooth loss classification: factors associated with a new classification in an adult population group]. Cien Saude Colet. 2015 Sep;20(9):2825-35. Portuguese. https://doi.org/10.1590/1413-81232015209.17322014

24. Lima CV, Souza JG, Oliveira BE, Noronha MS, Pereira AC, Probst LF. Falta de dentição funcional influencia na autopercepção da necessidade de tratamento em adultos: estudo de base populacional no Brasil. Cad Saude Colet. 2018;26(1):63-9. https://doi.org/10.1590/1414-462×201800010217

25. Vano M, Gennai S, Karapetsa D, Miceli M, Giuca MR, Gabriele M, et al. The influence of educational level and oral hygiene behaviours on DMFT index and CPITN index in an adult Italian population: an epidemiological study. Int J Dent Hyg. 2015 May;13(2):151-7. https://doi.org/10.1111/idh.12098

26. Nico LS, Andrade SS, Malta DC, Pucca Júnior GA, Peres MA. Pucca Júnior GA, Peres MA. Saúde Bucal autorreferida da população adulta brasileira: resultados da Pesquisa Nacional de Saúde 2013. Cien Saude Colet. 2016;21(2):389-98. https://doi.org/10.1590/1413-81232015212.25942015

27. Doroshina VY, Margaryan EG, Arakelyan MG. Specific age-related and gender related features in oral status. Stomatologia (Mosk). 2017;96(3):11-3. https://doi.org/10.17116/stomat201796311-13.

28. Rouxel P, Heilmann A, Aida J, Tsakos G, Watt RG. Social capital: theory, evidence, and implications for oral health. Community Dent Oral Epidemiol. 2015 Apr;43(2):97-105. https://doi.org/10.1111/cdoe.12141

29. Buss PM, Pellegrini Filho A. A saúde e seus determinantes sociais. Physis Rev Saúde Coletiva. 2007;17(1):77-93. https://doi.org/10.1590/S0103-73312007000100006 
30. Queiroz LR, Nascimento MA. Sentidos e significados da perda dentária na Estratégia Saúde da Família: uma realidade entre o pensar e o fazer. Rev Saúde Coletiva UEFS.. 2017;7(3):52-9. https://doi.org/10.13102/rscdauefs.v0i0.2117

31. Monteiro CN, Beenackers MA, Goldbaum M, de Azevedo Barros MB, Gianini RJ, Cesar CL, et al. Socioeconomic inequalities in dental health services in Sao Paulo, Brazil, 2003-2008. BMC Health Serv Res. 2016 Dec;16(1):683. https://doi.org/10.1186/s12913-016-1928-y

32. Queiroz RC, Portela MC. Vasconcellos MTL. [Brazilian Oral Health Survey (SB Brazil 2003): data do not allow for population estimates, but correction is possible]. Cad Saude Publica. 2009;25(1):47-58. Portuguese. https://doi.org/10.1590/S0102-311X2009000100005 